\title{
USOS OPOSITIVOS DO SÓ QUE: ABORDAGEM FUNCIONALISTA
}

Camilo Rosa Silva*

(iD) https://orcid.org/0000-0002-6230-8807

Como citar este artigo: SILVA, C. R. Usos opositivos do só que: abordagem funcionalista. Todas as Letras - Revista de Lingua e Literatura, São Paulo, v. 22, n. 1, p. 1-12, jan./abr. 2020. DOI: 10.5935/1980-6914/eLETLL2012269

Submissão: março de 2019. Aceite: agosto de 2019.

Resumo: Neste trabalho, apresento e discuto o comportamento opositivo da perífrase conjuncional só que. Detenho-me sobre dados coletados no Corpus D\&G da cidade de Natal, Rio Grande do Norte (FURTADO DA CUNHA, 1998). Para analisar a atuação do só que no campo da contrajunção, considero o sentido de quebra de expectativa (LONGHIN, 2003). O contexto, nessa perspectiva, influencia a função-significado exercida pelos componentes linguísticos, o que ativa a proeminência da função pragmática. A defesa de que discurso e gramática estão relacionados na construção dos sentidos mobilizados nas diversas situações de interação é, portanto, o norte do presente trabalho.

Palavras-chave: Gramática. Discurso. Uso. Gramaticalização. Só que. 


\section{INTRODUÇÃo}

' este trabalho, reflito sobre o comportamento opositivo da perífrase conjuncional só que. A discussão é recortada de uma pesquisa mais ampla que investiga as relações opositivas em português brasileiro. Aqui, tento verticalizar o olhar sobre usos coletados em amostras de língua falada do Corpus D\&G da cidade de Natal, Rio Grande do Norte (FURTADO DA CUNHA, 1998).

O repertório do português brasileiro para a expressão da oposição é bem estratificado, disponibilizando ao falante conectores como mas, porém, contudo, todavia, entre outros. Longhin (2003, p. 139) destaca que, a despeito dessa generosa lista, "a língua portuguesa criou a perífrase só que, um item conjuncional de natureza coordenativa, que tem a propriedade de estabelecer, entre os segmentos que articula, um tipo particular de contraste”.

Estudar os conectores partindo da perspectiva de que a língua em uso deflagra a emergencialidade da gramática significa defender que o contexto influencia a ativação da função-significado exercida pelos componentes linguísticos. Além disso, faz ressaltar a proeminência da função pragmática na construção dos textos e de seus sentidos.

A compreensão de que discurso e gramática estão relacionados e de que essa relação interfere nas diversas situações de interação é, portanto, o norte do presente trabalho. Com efeito, considero provável que os usos do só que em contextos de contraexpectativa, especialmente quando ativam noções no campo da ressalva ou da ironia, são prova relevante de que a gramática emerge do discurso e da pragmática.

O texto está organizado em três seções: na primeira, exponho conceitos e definições de conjunção formulados por autores de gramáticas e linguistas interessados no tema; na segunda, sumarizo discussões sobre a gramaticalização, tentando estabelecer diálogo com essa teoria e os estudos sobre a conexão textual. Na sequência, apresento alguns dados e tento formular generalizações a eles pertinentes.

\section{CONJUNÇÃo E/OU CONECTOR}

Nesta seção, recupero o conceito de conjunção, mobilizando alguns autores que dela tratam e tento afunilar a resenha prendendo-me ao domínio funcional da classe das conjunções opositivas. Vale ressalvar que, diferentemente do uso tradicional que se faz do termo, refiro-me à conjunção como a função semântico-textual e aos conectores como os itens linguísticos que a indiciam.

Para definir a conjunção, Neves (2002, p. 57) recorre à origem da gramática, citando Dionísio Trácio, que trata a referida classe como a palavra que "liga com ordenação o pensamento e revela os vazios da expressão". O autor grego ratifica a função conectiva da conjunção, defendendo sua condição não significativa, o que remete a remotas posições aristotélicas.

No latim popular, do qual se originou a maior parte das conjunções portuguesas, predominava a justaposição, o que é apontado como causa da extinção dos itens pertencentes a essa classe. Barreto (2002) menciona o caso das adversativas, que ao desaparecerem, cederam lugar ao advérbio magis. Ainda segundo 
essa autora, também as concessivas quamvis, etsi, licet, quanquam foram suprimidas, dando lugar a locuções com quod.

Na visão de Bechara (2009), as conjunções se dividem em conectores (as coordenadas) e transpositores (as subordinadas). À sua ótica, as conjunções coordenadas ligam orações que pertencem ao mesmo nível sintático e, por serem independentes umas das outras, podem aparecer em enunciados separados. Para o autor, as conjunções adversativas "enlaçam unidades apontando uma oposição entre elas" (BECHARA, 2009, p. 322). Ele afirma, ainda, que as adversativas por excelência são mas e porém, conjunções que acentuam a oposição; além de senão, que marca a incompatibilidade (BECHARA, 2009).

De acordo com Garcia (1992), as adversativas marcam oposição, apresentando, certas vezes, matizes semânticos de restrição ou ressalva. Ele percebe mudanças no processo evolutivo pelo qual passam as conjunções, afirmando que por causa de sua origem etimológica de natureza adverbial, "traço já muito esmaecido em mas e porém, mas ainda vivo nas restantes", adversativas, explicativas e conclusivas são menos gramaticalizadas (GARCIA, 1992, p. 18). Acredito que o autor se refira à condição de menor polivalência dessas conjunções quando cotejadas com o e, o nem e o ou.

Embora não seja corriqueiro, é possivel encontrar, nas obras de determinados autores, alguma preocupação em destacar nuanças comportamentais que revelam maior escopo funcional do que somente a relação semântica entre segmentos opostos. Cunha (1986), por exemplo, entende como uma manifestação dos valores afetivos no uso das conjunções o fato de o mas poder, ao largo de sua ideia básica de oposição, exprimir ideias de restrição, retificação, atenuação, compensação, adição e outros mais: "é particularmente importante o emprego desta conjunção (assim como o de porém) para mudar a sequência de um assunto, geralmente com o fim de retomar o fio de enunciado anterior que ficara suspenso" (CUNHA, 1986, p. 538).

Conforme defende Melo (1986, p. 106), os conectivos estabelecem ligações, concretizando relações, sejam de paralelismo sintático, sejam de dependência, quando o elemento subordinado for uma oração. Como existem dois tipos de relações sintáticas, há duas linhagens de conectivo: coordenantes e subordinantes. O primeiro tipo liga funções ou valores sintáticos iguais, enquanto o segundo estabelece relação de dependência entre a oração subordinada e o termo a que esta se refere.

Para Halliday e Hasan (1976, p. 250), “o significado básico da relação adversativa é 'contrário à expectativa'. A expectativa pode ser derivada do conteúdo do que está sendo dito, ou do processo de comunicação da relação falante-ouvinte". Os autores realizam uma análise dos conectores que, na lingua inglesa, cumprem a referida função, entre os quais se destacam yet, but, however, though. Essa forma de ver a oposição aproxima-se do que chamo aqui de contraexpectativa.

$\mathrm{Na}$ língua portuguesa, a conjunção mas é apontada pelos gramáticos como a que melhor caracteriza a relação opositiva da adversidade. Em pesquisa realizada em corpus de língua escrita, constituído por editoriais jornalísticos, observei usos diversos do item, com a manifestação de sutilezas e especificidades funcionais que, no entanto, jamais chegam a anular categoricamente sua natureza opositiva (SILVA, 2005)

Estudos funcionalistas têm observado que, quanto mais abundante for a utilização de uma forma linguística, mais provável será seu deslocamento para o 
exercício de funções inovadoras no discurso. Além disso, a repetição de itens ou construções linguísticas em determinadas posições estruturais, mesmo que estranha aos modelos consagrados, fixa e cristaliza novas funções para termos já existentes. Por óbvio, estou falando de gramaticalização. É dela que tratarei na seção que segue.

\section{A GRAMATiCAlizaÇÃo}

A presente pesquisa, debruçando-se sobre ocorrências opositivas, certamente, depara com comportamentos nos quais nuanças e entretons funcionais são flagrados, denunciando reais, possiveis ou potenciais mudanças no papel exercido pelo item só que. Nesta seção, invisto esforço na resenha da concepção teórica de gramaticalização e tento asfaltar o percurso que percorrerei quando da análise do item aqui em evidência.

Os estudos funcionalistas de inspiração mais cognitivista defendem que a natureza sistemática do desenvolvimento de processos mentais e comunicativos que governam o uso da língua determina a natureza sistemática da gramática. Nesses termos, a gramaticalização se materializa na interação falante/ouvinte por um viés não somente estrutural e discursivo, mas também cognitivo (BYBEE; PERKINS; PAGLIUCA, 1994).

Comungando o ponto de vista de Hopper e Traugott (2008, p. 2), reitero que a gramaticalização pode ser entendida tanto como um processo histórico como numa perspectiva sincrônica. Na primeira visão, investigam-se as formas gramaticais, perscrutando sua trajetória, da origem aos usos mais recentes, anotando as variações e mudanças que possam ter ocorrido ao longo do tempo. $\mathrm{Na}$ segunda, valorizam-se os padrões fluidos mobilizados na dinâmica da língua a partir de uma delimitação temporal. Essa segunda ordem de mudança é o fenômeno de que trato neste trabalho.

É clássica a definição formulada por Hopper e Traugott (1993, p. XV), em que afirmam que a gramaticalização consiste no "processo pelo qual itens lexicais e construções gramaticais passam, em determinados contextos linguísticos, a servir a funções gramaticais, e, uma vez gramaticalizados, continuam a desenvolver novas funções gramaticais". Teríamos, assim, uma perspectiva de distribuição dos itens linguísticos em funções mais e menos gramaticais, considerando um cline unidirecional. Por definição, sugere-se que a mudança percorre um caminho que vai da concretude à abstratização. Essa é uma concepção bastante questionada, mas que tem buscado sustentação em contingente de dados quantitativamente consistentes.

Hopper e Traugott (2008, p. 2) defendem a relevância e interferência do contexto como ativador específico da mudança, o que sugere ser possivel propor um mapeamento dos contextos de uso e distinguir aqueles mais favorecedores de determinadas inovações nos usos gramaticais. Considerando o conector com o qual trabalho neste texto, é oportuno destacar o quanto as singularidades contextuais interferem na escolha dos falantes, anotando, também, a tendência à especialização que influencia essas escolhas e consolida a ativação de subfunções específicas.

Traugott (2011) propôs três mecanismos representativos dos modos diversos pelos quais uma mudança ocorre. Seriam eles: reanálise, analogia e repetição. $\mathrm{Na}$ análise dos conectores contrastivos, interessa-me, mais de perto, dentre os 
mecanismos referidos, o da repetição, uma vez que ele reforça a atuação da frequência de uso tanto nos processos de mudança como nos de estabilidade linguística.

Também Bybee (2003) ressalta a relevância da repetição, pois, através dela, uma sequência de palavras ou morfemas pode ser automatizada como uma única unidade de processamento. A autora entende que há um tipo de frequência, por ela chamada de simbólica, que ativa o dispositivo para muitas mudanças, contemplando desde o desbotamento semântico até a eliminação de fronteiras entre palavras, o que seria determinado pela representação cognitiva dos falantes.

Além de defender a relevância da frequência de uso, elejo, aqui, como referência de análise, o princípio da estratificação, conforme proposto por Hopper (1991). Ele pode ser compreendido como um fenômeno em que determinados domínios funcionais admitem a existência de múltiplas formas no exercício de uma única função. $\mathrm{Na}$ visão do referido autor,

[...] dentro de um amplo domínio funcional, novas camadas emergem continuamente. Quando isso acontece, as camadas mais antigas não são necessariamente descartadas, mas podem permanecer coexistindo e interagirem com as camadas mais recentes (HOPPER, 1991, p. 22).

Teríamos, nesse contexto, camadas competindo pela preferência do falante, sendo elas intercambiáveis em certos contextos. Desse modo, camadas são compreendidas como um tipo de variabilidade (HOPPER; TRAUGOTT, 2008).

Com essa síntese tentei situar o processo de gramaticalização da perifrase só que, para revelar, a partir dos dados analisados, as especificidades de sentido contextual e pragmático das escolhas provavelmente conscientes dos falantes. De tal sorte que serão consideradas as tendências à especialização funcional do item, uma vez que elas parecem organizar o modo de dizer na direção de sentidos determinados/pretendidos. Em linhas gerais, esse ponto será tratado na próxima seção.

\section{O “SÓ QUE" EM SITUAÇÃo DE USO}

Embora não pretenda controlar quantitativamente os dados, visto não ser esse o objetivo do presente texto, tento manter a coerência, apresentando inicialmente um panorama da frequência de uso, posto que já ressaltei sua relevância para a consolidação dos processos de mudança linguística. No corpus em análise, contabilizo 58 ocorrências do só que, as quais se distribuem pelos quatro níveis de escolaridade selecionados para a amostra. O item está presente nas duas modalidades de uso da língua - embora aqui me interessem mais os dados de oralidade -, como também em todos os "gêneros" que compõem o corpus: narrativa de experiência pessoal; narrativa recontada; descrição de local; relato de procedimento; relato de opinião.

Parto, nesta análise, do pressuposto de que a função básica de uso do só que é a de contraexpectativa. O estudo de Longhin (2003) sobre a perífrase em tela não deixa pairar dúvidas a respeito dessa característica. Nas palavras da autora:

SÓ QUE pode veicular diferentes acepções de sentido, [...]. Apesar dessas variantes contextuais, creio que é possível recuperar para SÓ QUE um sentido básico e invariável, que é sempre preservado, a saber, aquele de contraste por quebra de expectativa (LONGHIN, 2003, p. 119-120). 
Recorrendo a Heine et al. (1991), Longhin (2003) comenta: "A quebra de expectativa, nesse sentido, equivale a toda a situação em que, de alguma forma, há divergência entre aquilo que se diz e aquilo que é considerado normal". A autora propõe cinco funções para o só que, a saber: marcador de diferença; marcador de acontecimento inesperado/indesejado (surpresa); marcador de refutação; marcador da não satisfação de condições e marcador de contra-argumentação ${ }^{1}$.

A noção de "quebra de expectativa", portanto, está relacionada àquilo que, dentro de determinado contexto, é esperado para expressar a percepção acerca de um estado de coisas. Ela não decorre diretamente da incompatibilidade semântica entre orações, mas de aspectos ligados ao contexto pragmático. Isso inclui as avaliações, as crenças, as inferências e as pressuposições dos falantes.

Quando assumo a noção de contraexpectativa, refiro-me às situações nas quais o falante se prospecta em direção ao universo cognitivo e contextual de seu interlocutor. Nessa perspectiva, ele direciona argumentos não àquilo que é expresso na estrutura do texto, mas ao que se arrisca a prever acerca do pensamento do outro. De acordo com tal lógica, é preciso considerar que, no calor da interação, não é incomum os interlocutores nutrirem expectativas distintas e cometerem equívocos influenciados por sua visão de mundo e história de vida.

Nos dados do corpus analisado, o valor básico do só que é, realmente, o de contraste por quebra de expectativa. Vejamos o que dizem os dados:

(1) ... e ao descobrir ... o outro também faz uma descoberta ... que ele era o cara tão odiado pela família ... o advogado ... né ... então resolve que vai fazer uma trégua ... né ... os dois ... se ele contasse pra família quem era ele ... o assassino ... o cara lá ... ele também contava que ele era o cara tão odiado pela família ... né ... que até então ele era um cara bem quisto ... né ... um trabalhador ... um cara honesto ... trabalhador ... morava com as meninas ... uma família e tudo ... só que a polícia tava se aproximando ... né ... tá chegando ... tá fechando o cerco ... com esse cerco fechado ... o que aconteceu ... eles começaram a discutir ... né ... e aí a menina descobriu quem era ele ... a menina descobriu quem era o cara procurado pela polícia e ia entregá-lo ... quando ela ia entregá-lo à polícia ... ele a ameaçou de morte ... quando ele ameaça de morte a menina ... (gênero: narrativa recontada).

No contexto de uso de (1), a contraexpectativa se materializa quando a polícia desmascara um rapaz até então considerado por quem não o conhecia bem como um modelo de bom moço. O só que delimita as informações para, a partir dele, introduzir-se uma revelação que vai de encontro ao que se conhecia sobre o personagem e que, consequentemente, não seria o esperado para o desfecho do episódio.

Vale ressaltar que, em dados de lingua oral, essa contraexpectativa não se estrutura obrigatoriamente logo após o conector opositivo. Ele, não raramente, introduz um contexto mais amplo, preparando a informação inesperada que vai desconstruir uma imagem projetada no segmento precedente.

1 Como não vou utilizar, aqui, essa classificação, remeto o leitor nela interessado ao trabalho da autora: Longhin (2003). 
Vejamos outra ocorrência:

(2) ... então a gente ficou lá mais ou menos umas duas horas conversando na quadra ... depois nós voltamos ... no mesmo dia aconteceu uma coisa interessante porque ... as muriçocas só paravam de aperriar quando a gente ... de encher o saco ... quando a gente deixava a luz acesa ... só que com a luz acesa a gente não conseguia dormir ... então a gente terminou passando a noite toda acordada ... a gente foi lá pra fora pegou um lanche e foi lanchar lá fora com os meninos (gênero: narrativa de experiência pessoal).

Esse dado também ilustra o fato de a oposição introduzida pelo só que não se estabelecer entre as informações já expressas e as que estão por vir no texto, tomando como referência uma sequencialidade natural de fatos em um mundo real/possivel/imaginável.

Tal qual ocorre na maioria dos usos de contraexpectativa, esse se dá num contexto em que o só que seria intercambiável com o mas. Entretanto, se feita essa escolha, provavelmente o efeito de sentido seria distinto, uma vez que divergiriam as possibilidades interpretativas autorizadas pelo acionamento da perífrase. Ao mencionar o recurso da intercambialidade, pretendo defender que não seria impossível um enunciado em que o mas substituísse o só que, mesmo não preservando os efeitos de sentido e, sim, um sentido básico. Tem sutilezas semânticas que se alteram na troca de um conector pelo outro e isso só confirma a inexistência de sinônimos perfeitos, mesmo em se tratando de usos mais gramaticais.

Como já dei a entender, quando falo em conectores opositivos, observo que a essência de um enunciado dessa natureza reside em apontar aspectos contrapostos a respeito daquilo que é informado entre os segmentos, considerando a interposição do conector na fronteira compartilhada pelos conteúdos contrastantes. Portanto, lidamos aqui com possibilidades sintáticas, mas básica e preponderantemente, também, com percepções semânticas, que se encorpam nos domínios discursivo e pragmático. De modo geral, a diversidade dos conteúdos presentes em contextos opositivos se reveste de valores como: contraste, objeção, compensação, ressalva, revisão, retificação, comparação, polarização, exclusão, inclusão, exclusividade, entre outros.

Assim, ao lado de um leque de camadas de conectores disponibilizados ao falante para construir seu enunciado de cunho opositivo, há um conjunto de nuanças discursivas, contextuais e pragmáticas que podem alterar a essência do que ele diz ou do que pretende dizer, e isso é relevante para determinar as escolhas feitas na interação.

Não à toa, Hopper (1991) já alerta que as diversas formas que servem a uma mesma função podem ter um significado ligeiramente diferente ou simplesmente ser reconhecidas como alternativas de registros estilísticos e sociolinguísticos. Considerando que matizes contextuais são semanticamente ativados, a seleção de um item em detrimento de outro(s) é sinal de especialização, o que, para mim, significa restrição à intercambialidade.

Os dados do D\&G confirmam a percepção já revelada nos estudos citados de que o só que se mantém como ativador de quebra de expectativa. Entretanto, ele pode ampliar o escopo de atuação para subfunções argumentativas mais específicas, diretamente relacionadas ao domínio pragmático. 
A constatação de que a frequência de uso do só que é mais elevada em dados da língua falada do que nos da escrita parece assinalar uma vocação à especialização da perífrase em contextos de contraexpectativa evidenciados na modalidade oral. O fato de o item, nesses contextos, ser intercambiável com o prototípico mas e, mesmo assim, ser o preferido é indício dessa especialização discursivo-pragmática, mas, também, sinal de que o processo de mudança ainda está em curso.

Dentre as funções que emergem como mais produtivas no corpus, em se tratando do só que, destaco duas que me parece não terem sido detectadas nos estudos já citados: introdutor de ressalva e ativador de ironia.

a) introdutor de ressalva:

(3) I: [...] Por enquanto está funcionando lá no Ferro Cardoso esse ... esses primeiros anos né ... desses cursos ... tem o ... a terceira unidade que funciona lá na ... na avenida Salgado Filho ... antigo Híper Veículos que é ... só o curso de biologia ... que funciona no ... nos dois turnos ... o único curso que funciona em dois turnos ... o vespertino e o noturno e:: é ... lá tem né ... lá tem tudo que tem lá na ... na ... Na ... na primeira unidade só que bem resumido né? sim ... fora os ... sim ... fora os laboratórios de biologia que num tem lá né ... mas tem laboratório de biologia ... as salas de aula né ... os banheiros ... o estacionamento ... dos professores ... os professores só da UNIPEC né ... e ... lá ... essa ... essa unidade... (gênero: descrição de lugar).

Em (3), o informante coloca em perspectiva as instalações físicas de duas unidades de um centro de ensino por ele frequentado, explicando que a estrutura existente em uma é igual à da outra, mas faz a ressalva de que numa delas tudo é "bem resumido". Pelo encaminhamento comparativo dado à descrição, o esperado era que tudo fosse equivalente ou aproximado em relação à estrutura dos dois lugares. Entretanto, essa expectativa é contrariada com a ressalva que aponta a divergência: amplo/resumido.

Aqui, considero a ressalva um subtipo de oposição que não parece ser incongruente com a contraexpectativa. Pelo contrário, ela pode ser demandada exatamente para apontar intercorrências e fatores inesperados em eventos/fatos/ percepções situados no mundo extralinguístico, os quais são reportados na sequencialidade do fluxo textual não sem antes terem passeado pelo domínio cognitivo do enunciador.

b) ativador de ironia:

(4) .. é questão de ter investimento na educação ... se investisse mais na ... na ... no ensino público ... obviamente teria:: porque a capacidade desse pessoal é a mesma do particular ... inclusive ... tem professor que ensina em colégio particular e em colégio público ... então ... só que agora em colégio particular ele recebe muito mais ... dá vontade de ensinar ... e no público não ... então ... se tiver esse incentivo ... aî tem a questão política que eu te expliquei ... só que não se tem ... (gênero: relato de opinião).

O informante realiza, em (4), um percurso argumentativo em que vai selecionando fatores favoráveis a um determinado ponto de vista, mas o desfecho, licenciado pelo só que, ativa a invalidação daquilo que sustentaria sua tese. Nesse caso, o item adjunge-se à negação e o verbo é expresso na sequência. É 
razoável hipotetizar que tenha sido em contextos semelhantes a esse que se originou a construção cristalizada "só que não" (SQN).

Teríamos um cline assim esboçado:

só que...não tem > só que não...tem > só que não

A função de ativador de ironia emerge em situações nas quais o SQN, altamente produtivo em interações praticadas nas redes sociais, mas não exclusivo delas, detém importante teor expressivo-comunicativo. Os usos da perífrase, nos citados ambientes virtuais, geralmente são encaminhamento de conclusão de tópico, quando o falante invalida a veracidade de tudo que acabou de enunciar acerca de um determinado tema. Também é comum aparecer na voz responsiva do interlocutor, em tom de retruque, quando esse quer dar a entender que não reconhece um valor (de verdade) positivo para o que lhe foi enunciado. Importa anotar que esses registros on-line são um tanto híbridos em relação à dualidade escrita/oralidade e que esses usos são frequentes em interações orais caracterizadas pela informalidade entre os interlocutores.

Nessa dialética inescapável, o só que vai se acomodando em contextos de contraexpectativa e parte para usos mais abstratizados, como são os que emergem em discursos de cunho irônico. Ao agregar o não, compondo com ele a construção só que não, já na sua forma siglônima (SQN), está indicada a necessidade de ativação do módulo ironia para compreender o componente discursivo do que é enunciado. É o processo de gramaticalização como resultado dos padrões emergentes de uso, levando itens já gramaticais a atuarem em funções ainda mais gramaticais.

Por fim, exponho um dado no qual o só que se apresenta precedido pelo mas:

(5) I: tinha aparecido também ... mas se bem que ele apareceu como se fosse vivo ... que ela foi pegar e tudo né ... e ele sem saber como é que foi aquilo né ... ai ficou com o gato ... mas só que o gato num ... num ... num... estranhava ... só se dava bem com as crianças (gênero: narrativa recontada).

Para detectar a contraexpectativa, nesse caso, é preciso considerar, acessando o conhecimento de mundo, o que se espera de um animal de estimação, de modo que constatar estranhamento em relação a seu "dono/provedor" sinaliza contraste com o que é esperado.

Usos do só que contíguos ao mas podem apontar a gênese de seu valor opositivo, visto que o contexto, a despeito da presença da perífrase, já se impõe claramente adversativo. Por outro lado, tais usos revelam o estágio parcial da gramaticalização do item nesse domínio. O só que engorda o valor opositivo do mas, ao mesmo tempo que ainda sugere preservar o papel focalizador do só. Isso reforça a constatação de que o processo de gramaticalização encontra-se em estágio não consolidado, a se aceitar que recorrer à contiguidade, em contextos de sinonímia gramatical, pode revelar a compreensão do falante de que o uso de um dos itens, isoladamente, não daria conta de expressar determinada função.

Em análises que considerem a língua em uso, é aconselhável observar o contexto e não partir de uma classificação apriorística que tome o valor semântico dos conectores em si mesmos, conforme congelados nos compêndios lexicológicos ou gramaticais. Paiva (1991, p. 156) parece também defender esse ponto de vista ao afirmar que os conectores assimilam propriedades discursivo-funcionais dos contextos em que se inserem, de modo que, "a longo prazo, as propriedades 
passam a ser traços inerentes a esses elementos". Isso quer dizer que o teor semântico apresentado em contextos específicos, nos quais o uso de certos conectores é recorrente, acaba se adesivando àquela forma, que passa, ela própria, a assumir o papel de condutora desse valor semântico-discursivo. A essa condição não fogem os usos neológicos e a consequente renovação expressiva das conexões sintáticas e textuais.

Por compartilhar essa percepção, defendo que a perífrase só que funciona em contextos opositivos, ativando a noção discursiva de contraexpectativa e nela se especializando, diferenciando-se, por isso, do mas. Embora possam ser intercambiáveis, nem sempre isso é factivel, especialmente devido a uma polifuncionalidade mais produtiva do mas, que não é assumida pelo só que.

Essa discussão leva a concluir que, no uso corrente da lingua, as regularidades são mobilizadas por pressões de cunho cognitivo e pelas próprias pressões intrínsecas ao sistema. Assim, as interpretações realizadas pelos falantes são organizadas no domínio cognitivo, o que ativa o aspecto regularizador e fixador das estruturas. Por outro lado, a variação é fruto, dentre outras motivações, da natureza criativa do discurso e da permanente busca por expressividade que acompanha a produção linguística.

\section{CONSIDERAÇÕES FINAIS}

Os usos linguísticos não ocorrem aleatoriamente. As escolhas dos falantes duelam entre o que já está estabilizado e o interesse na expressividade, via inovação. Assim, testa-se a utilização de formas antigas para o exercício de novas funções. A essa realidade não fogem os conectores de oposição; o item só que, por exemplo, concorre, em contextos de contraexpectativa, com o prototípico mas, embora haja nuanças funcionais que apontam para efeitos de sentido específicos em cada uso.

Geralmente, as conjunções são apresentadas, nas gramáticas tradicionais, como uma classe invariável cuja função restringe-se a ligar orações ou termos coordenados no interior de uma oração. Seus aspectos semânticos, argumentativos e discursivos raramente são contemplados nessas abordagens. Só que tal perspectiva é muito redutora em relação ao que efetivamente a língua realiza valendo-se de seus conectores.

Toda forma linguística realiza funções não apenas das intenções e dos conteúdos verbalizados, mas também das informações pragmáticas do destinatário e de seu conhecimento a respeito das intenções do enunciador. É razoável defender, portanto, a interferência do contexto discursivo-pragmático nos processos de gramaticalização. Os falantes não interagem somente pela lingua, mas, também, com a língua. Eles e ela participam de modo cooperativo da simbolização dos referentes pela via da palavra e dos diferentes significados construídos em contextos particulares.

\section{OPPOSITIVE USES OF "SÓ gUE": A FUNCTIONAL APPROACH}

Abstract: In this paper, I present and discuss the oppositional behavior of periphrasis "só que". I dwell on a sample of data collected in the Corpus D\&G of the city of Natal, State of Rio Grande do Norte (FURTADO DA CUNHA, 1998). To 
analyze the appliance of only that in the field of counterjunction, I consider that the sense of breaking of expectation is a function inherently related to the use of the item (LONGHIN, 2003). The context, in this perspective, influences the function-meaning exerted by the linguistic components, which activates the prominence of the pragmatic function. The defense that discourse and grammar are related in the construction of the senses mobilized in diverse situations of interaction is, therefore, the north of this paper.

Keywords: Grammar. Discourse. Use. Grammaticalization. "Só que”.

\section{REFERÊNCIAS}

BARRETO, T. M. M. Observações sobre as conjunções no século XVI. In: MATTOS E SILVA, R. V.; MACHADO FILHO, A. V. L. (org.). O Português Quinhentista: estudos lingüísticos. Salvador: Edufba/UEFS, 2002. v. 1, p. 161-193.

BECHARA, E. Moderna gramática portuguesa. 37. ed. rev., ampl. e atual. Rio de Janeiro: Nova Fronteira, 2009.

BYBEE, J. Mechanisms of change in grammaticalization: the role of frequency. In: JOSEPH, B. D.; JANDA, R. (ed.). Handbook of historical linguistics. Oxford: Blackwell Publishers, 2003. p. 602-623.

BYBEE, J.; PERKINS, R.; PAGLIUCA, W. The evolution of grammar. tense, aspect, and modality in the languages of the world. Chicago: Chicago Press, 1994.

CUNHA, C. Gramática da lingua portuguesa. Rio de Janeiro: FAE, 1986.

FURTADO DA CUNHA, M. A. (org.). Corpus Discurso \& Gramática: a língua falada e escrita na cidade do Natal. Natal: EDUFRN, 1998.

GARCIA, O. M. Comunicação em prosa moderna. São Paulo: FGV, 1992.

HALLIDAY, M. A. K.; HASAN, R. Cohesion in english. New York: Longman, 1976. HEINE, B. et al. Grammaticalization: a conceptual framework. Chicago: The University of Chicago Press, 1991.

HOPPER, P. On some principles of grammaticazation. In: TRAUGOTT, E.; HEINE, B. Approaches to grammaticalization. Amsterdan: Benjamins, 1991. v. 1, p. 17-37.

HOPPER, P.; TRAUGOTT, E. Grammaticalization. Cambridge: Cambridge University Press, 1993.

HOPPER, P.; TRAUGOTT, E. C. Grammaticalization. Cambridge: Cambridge University Press, 2008.

LONGHIN, S. R. A gramaticalização da perífrase conjuncional "só que". 2003. 212 f. Tese (Doutorado em Linguística) - Universidade Estadual de Campinas, Campinas, 2003.

MELO, G. C. Gramática fundamental da língua portuguesa. 3. ed. Rio de Janeiro: Ao Livro Técnico, 1986.

NEVES, M. H. M. A Gramática: história, teoria e análise. São Paulo: Editora Unesp, 2002.

PAIVA, M. C. Ordenação de cláusulas causais: forma e função. 1991. 238 f. Tese (Doutorado em Linguística) - Universidade Federal do Rio de Janeiro, Rio de Janeiro, 1991. 
LÍNGUA E LINGUÍSTICA

SILVA, C. R. Mas tem um porém...: mapeamento funcionalista da oposição e seus conectores em editoriais jornalísticos. 2005. 272 f. Tese (Doutorado em Letras) - Universidade Federal da Paraíba, João Pessoa, 2005.

TRAUGOTT, E. C. Grammaticalization and mechanisms of change. In: HEINE, B.; NARROG, H. (ed.). The Oxford handbooks of grammaticalization. Oxford handbooks online. 2011. 